\title{
Physical Modeling of Untrenched Pipeline Breakout From Sand-Bed in Ocean Currents
}

Conference Paper · January 2010

DOI: 10.1115/OMAE2010-20183

READS

14

6 authors, including:

Fu-Ping Gao

Chinese Academy of Sciences

60 PUBLICATIONS 387 CITATIONS

SEE PROFILE 


\title{
PHYSICAL MODELING OF UNTRENCHED PIPELINE BREAKOUT FROM SAND- BED IN OCEAN CURRENTS
}

\author{
Shu-Ming Yan ${ }^{1,2}$, Fu-Ping $\mathrm{Gao}^{1}{ }^{*}$, Jing $\mathrm{Cao}^{3}$, En-Yong Zhang ${ }^{3}$, Guo-Hui $\mathrm{Li}^{2}$, Ying-Xiang $\mathrm{Wu}^{1}$ \\ ${ }^{1}$ Key Laboratory for Hydrodynamics and Ocean Engineering, Institute of Mechanics, Chinese Academy \\ of Sciences, Beijing, China \\ ${ }^{2}$ Crossing Department, China Petroleum Pipeline Engineering Corporation, Langfang, China \\ ${ }^{3}$ CNOOC Research Center, Beijing, China
}

\section{ABSTRACT}

The ultimate lateral soil resistance for pipe losing lateral stability on a sandy seabed under the action of ocean currents is investigated with a newly developed test facility by employing mechanical actuators to simulate hydrodynamic loads on the pipe. Two kinds of constraint conditions, i.e. anti-rolling pipe and freely-laid pipe, are taken into account, respectively. The experimental observations indicate that, the horizontal lateral soil resistance increases gradually to its maximum (ultimate) value when the additional settlement is fully developed. The buildup of the ultimate lateral soil resistance to the anti-rolling pipe benefits from not only the additional settlements but also the sand-particle collections in front of the moving pipe, especially for the anti-rolling pipes. The lateral-soil-resistance coefficient for the anti-rolling pipe is much larger than that for the freely-laid pipe. The pipe surface roughness also affects the lateral stability of anti-rolling pipes. A comparison is made between present mechanical-actuator tests and the previous water-flume tests, indicating the results of two types of tests are comparable and the local scour may reduce the pipe lateral stability in ocean currents.

\section{NOMENCLATURE}

$C_{D} \quad$ Drag coefficient

$C_{L} \quad$ Lift coefficient

$C_{u} \quad$ Uniformity coefficient of sand

$d_{50} \quad$ Mean grain size of sand

$d_{s} \quad$ Diameter of sand particles

$D \quad$ Pipeline outer diameter

$D_{r} \quad$ Relative density of sand

$e \quad$ Settlement of the pipe $e_{0} \quad$ Initial settlement of the pipe

$e_{y} \quad$ Settlement of the moving pipe

$e_{\mathrm{m}} \quad$ Maximum settlement of the pipe

$F_{D} \quad$ Horizontal drag force on the pipe

$F_{H} \quad$ Lateral soil resistance to the pipe

$F_{L} \quad$ Vertical lift force on the pipe

$\mathrm{Fr}_{c r} \quad$ Critical Froude number for pipe on-bottom instability

$F_{u} \quad$ Ultimate lateral soil resistance

$S_{x} \quad$ Horizontal displacement of the pipe

$G \quad$ Non-dimensional submerged weight of the pipeline

$k \quad$ Pipe surface roughness

$U \quad$ Effective water particle velocity

$U_{c r} \quad$ Critical flow velocity for pipe on-bottom instability

$W_{S} \quad$ Submerged pipeline weight

$\gamma^{\prime} \quad$ Buoyant unit weight of soil

$\theta \quad$ Inclination angle of mechanical loading

$\rho_{\text {sat }} \quad$ Mass density of saturated sand

$\rho_{w} \quad$ Mass density of fluid

$\lambda \quad$ An identifier for end constraint conditions of the pipe

$\phi \quad$ Internal frictional angle of sand

$\eta \quad$ Lateral-soil-resistance coefficient

\section{INTRODUCTION}

The submarine pipeline on-bottom stability in the severe ocean environments involves the "flow-pipe-soil" interaction [1]. To avoid the occurrence of pipeline on-bottom instability, i.e. the breakout of the pipe from its original site, the seabed must provide enough soil resistance to balance the hydrodynamic loads upon the untrenched pipeline. When a pipeline is installed on the seabed, e.g. during installation as

\footnotetext{
* Professor and Corresponding Author, fpgao@imech.ac.cn
} 
well as in the operational phase, its on-bottom stability is largely related to the interaction between the pipeline and the neighboring soil. For pipeline geotechnical engineers, one of the main concerns for pipeline on-bottom stability design is to properly determine the ultimate soil resistance in the severe ocean environments [2].

In the past few decades, the pipe-soil interactions have attracted much interest from pipeline researchers and designers. Before 1970s, Coulomb friction theory was firstly employed to estimate the friction force between pipeline and soil under the action of ocean waves. Actually, Coulomb friction theory is far from the realistic pipe-soil interaction. Lyons [3] experimentally explored the wave-induced stability of the untrenched pipeline, and concluded that the Coulomb friction theory was not suitable to describe the wave-induced interaction between pipeline and soil, especially when the cohesive clay is involved. In the 1980's, a few large projects had focused particularly on solving wave-induced pipe-soil interaction problems, such as the PIPESTAB project [4], the AGA project [5] and a project at DHI [6]. Numerous experimental studies on the lateral stability of untrenched pipelines have been carried out with mechanical actuators methods [4-7]. Among these, Wagner et al. [4] improved the Coulomb friction theory into an empirical pipe-soil interaction model, in which the total lateral resistance was assumed to be the sum of the Coulomb friction component and the soil passive resistance component. Brennoden et al. [5] further proposed an energy-based pipe-soil interaction model, in which the soil passive resistance component is related to the work done by the pipe during its movement. Using the PIPESTAB, AGA and DHI experimental data, Verley et al. [8, 9] developed a pipe-soil interaction model, taking into account the pipe penetration into the soil when subjected to oscillatory forces in waves. Recently, a series of centrifuge tests were conducted on the pipe-soil interaction for a shallowly embedded pipeline in calcareous sand [10]. The aforementioned studies focused mainly on the wave-induced pipeline on-bottom stability, in which cyclic loading methods were employed for the simulation of wave loads on the pipe.

With the oil and gas exploitation moving into deeper waters, ocean current becomes the prevailing hydrodynamic load for on-bottom stability of submarine pipelines. Although the pipe on-bottom stability in currents seems less complex than in waves, till now, the underlying physical mechanism has not been well revealed [1].

This paper aims to explore the physical mechanism of pipeline on-bottom stability in ocean currents. The ultimate lateral soil resistances to the untrenched pipes with two kinds of constraint conditions, i.e. freely-laid pipe and anti-rolling pipe, are studied experimentally. Furthermore, a comparison is made between the results of the mechanical actuator experiments and those of the previous water-flume tests.

\section{DIMENSIONAL ANALYSES}

The ocean current induced pipeline on-bottom stability on a sandy seabed is an interaction between the flow, pipe and soil. The ultimate lateral soil resistance $\left(F_{u}\right)$ is mainly related to the following characteristic parameters of the pipe, the soil, and the hydrodynamic load:

$$
F_{u}=f\left(W_{s}, D, k, \rho_{\text {sat }}, \rho_{w}, d_{s}, D_{r}, \phi, g, \tan \theta, e_{0}, \lambda \ldots\right)
$$

where $W_{S}$ is the submerged weight of the pipeline per meter; $D$ is the outer diameter of pipeline; $k$ is the roughness of the pipe surface; $\rho_{\text {sat }}$ is the mass density of saturated sand; $\rho_{w}$ is the mass density of fluid; $d_{s}$ is the diameter of sand particles; $D r$ is the relative density of sand; $\phi$ is the internal frictional angle of sand; $g$ is the gravitational acceleration; $\tan \theta$ is the ratio of the lift (vertical) and the drag (horizontal) force on the pipe (see Fig. 2); $e_{0}$ is the initial settlement of the pipe, which is a deduced (not independent) variable if the pipe settles into the soil under its self-weight; $\lambda$ represents the end constraint conditions of the pipe. In this study, two kinds of end constraints are taken into account, i.e. freely-laid pipes and anti-rolling pipes.

Based on the Buckingham Pi-Theorem in the dimensional analysis theory, the dimensionless variables can be obtained from Eq. (1) as follows:

$$
\eta=f^{\prime}\left(G, \frac{k}{D}, \frac{\rho_{s a t}}{\rho_{w}}, \frac{D}{d_{s}}, D_{r}, \phi, \tan \theta, \frac{e_{0}}{D}, \lambda \ldots\right)
$$

where the lateral-soil-resistance coefficient $(\eta)$ is defined as the ratio of the ultimate lateral soil resistance to the vertical pipe-soil contact force, i.e.

$$
\eta=\frac{F_{u}}{W_{s}-F_{u} \tan \theta}
$$

$G$ is the non-dimensional submerged weight of the pipe:

$$
G=\frac{W_{S}}{\gamma^{\prime} D^{2}}
$$

where $\gamma^{\prime}=\left(\rho_{\text {sat }}-\rho_{w}\right) g$ is the buoyant unit weight of the saturated sand; $k / D$ is the relative roughness of the pipe surface; $\rho_{\text {sat }} / \rho_{w}$ is the specific gravity of the saturated sand, i.e. the ratio of the density of the saturated sand to that of the pore water; $D / d_{s}$ is the ratio of pipe diameter to sand diameter; $e_{0} / D$ is the dimensionless initial settlement; $D_{r}$ is the relative density of sand bed. In this study, the influence of pipe surface roughness, pipe end constraints on the pipe on-bottom stability are examined intensively.

\section{EXPERIMENTAL SETUP AND TESTING METHOD}

\subsection{Hydrodynamic Loads on a Pipe Resting on Seabed}

To efficiently simulate the ocean currents induced hydrodynamic loads upon a submarine pipeline is crucial for evaluating pipeline lateral on-bottom stability. According to Morison's equation, the horizontal and lift (vertical) components of the steady flow induced hydrodynamic forces are written as follows: 


$$
\begin{aligned}
F_{D} & =0.5 C_{D} \rho_{w} D U^{2} \\
F_{L} & =0.5 C_{L} \rho_{w} D U^{2}
\end{aligned}
$$

where $F_{D}$ is the horizontal drag force, $F_{L}$ is the vertical lift force, $C_{D}$ is the drag coefficient, $C_{L}$ is the lift coefficient, $U$ is the effective water particle velocity. Variations of the drag and lift coefficients, $C_{D}$ and $C_{L}$, with the Reynolds number (Re) for various values of pipe surface roughness have been obtained by Jones (1978) [11]. As shown in Fig.1, with Re increasing from $3.0 \times 10^{4}$ to $1.0 \times 10^{6}$, both the drag coefficient $C_{D}$ and the lift coefficient $C_{L}$ decrease gradually to constant values with similar trends. The resultant hydrodynamic load upon the pipe is obliquely upwards with the inclination angle:

$$
\theta=\arctan \left(F_{L} / F_{D}\right) \approx \arctan \left(C_{L} / C_{D}\right)
$$

Referring to the experimental results for the case of $k / D=$ $7.0 \times 10^{-4}$ (see Fig. 1), the inclination angle $(\theta)$ is approximately between $53^{0} \sim 57^{0}$.

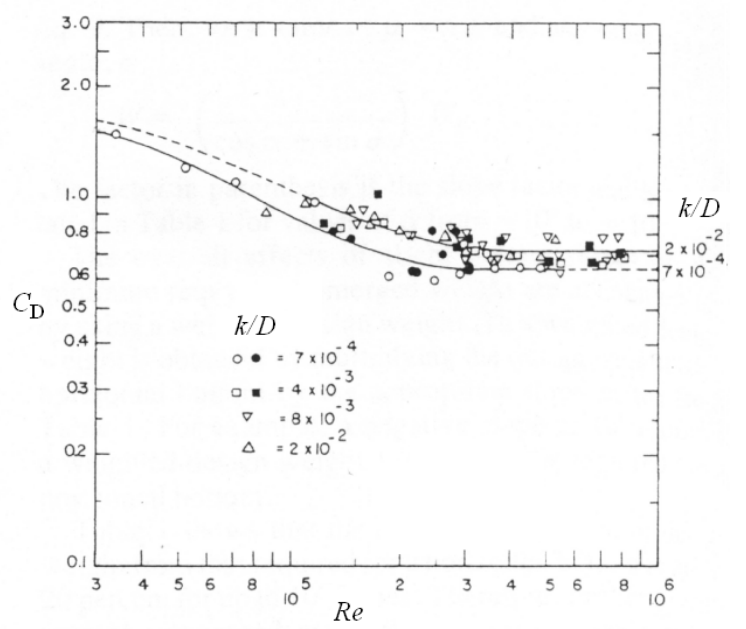

(a)

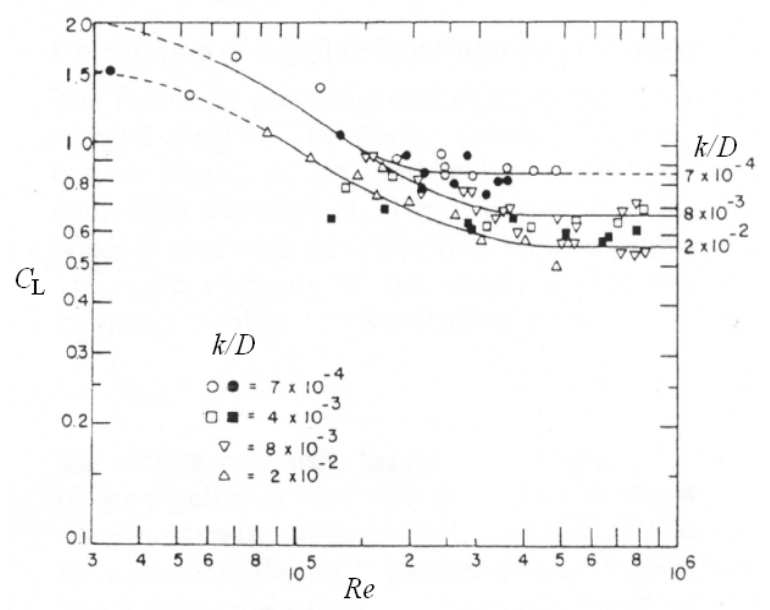

(b)

Fig.1 Recommended effective hydrodynamic coefficients for a pipe resting on the sea bottom: (a) drag coefficient, (b) lift coefficient (After Jones [11])

\subsection{Mechanical Actuator Simulations}

For a pipeline laid on the seabed under the action of ocean currents, there exists a dynamic balance between the submerged weight of the pipe, the hydrodynamics forces (including the horizontal drag force $F_{D}$ and the vertical lift force $F_{L}$ ), and the soil resistances (including the lateral soil resistance $F_{H}$ and the vertical supporting force). When the ultimate lateral soil resistance is not able to balance the horizontal drag force, the pipe would breakout from its original site, i.e. the lateral instability occurs.

As aforementioned, the mechanical actuator simulation method has ever been employed in the previous studies, but which were mainly for wave-induced pipeline on-bottom stability. An updated experimental facility has recently been designed and constructed, as depicted in Fig. 2.

The facility mainly consists of a sand box with glass wall, a mechanical actuator, and the measurement system, etc. (see Fig. 2). In the sand box ( $2 \mathrm{~m}$ long, $0.5 \mathrm{~m}$ wide and $0.6 \mathrm{~m}$ deep), a saturated sand-bed with certain relative density can be prepared by employing the sand-raining technique. Note that, in the process of the tests, the sands in the box were kept saturated with approximately $2 \mathrm{~cm}$ of free water on the surface. In the mechanical actuator system, a stepper motor was capable of generating inclined force onto the test pipe via a cable passing through a fixed pulley, for simulating steady currents induced drag force and lift force on the pipeline. Meanwhile, a lifter was used to adjust the inclination angle, which was maintained in the range of $53^{0} \sim 57^{0}$ according to the above analyses. In the measurement system, two laser displacement transducers (LDT-1 and 2, see Fig. 2) were employed for the non-contact measurement of pipe displacements, i.e. LDT-1 is for the horizontal displacement of the test pipe, and LDT-2 for vertical settlement; a tension load cell was used for the measurement of the exerted inclined loads onto the test pipe. In the process of experiments, the pipe displacements and the exerted forces were measured simultaneously. The movement of the pipe was also recorded concurrently through the transparent glass wall with a digital video camera.

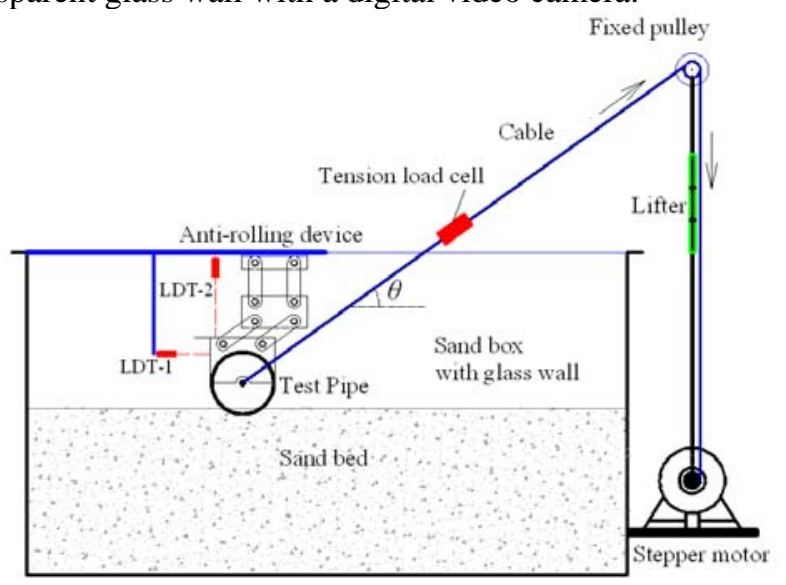

Fig.2. Schematic diagram of the experimental setup for pipesoil interaction 
Two values of the diameter of pipelines with various submerged weights were used, i.e. $D=0.20 \mathrm{~m}, 0.15 \mathrm{~m}$, respectively. Two values of surface roughness of the test pipes were examined, i.e. $k=10.6 \times 10^{-5} \mathrm{~m}$ (note: $k / D \approx 6.0 \times 10^{-4}$ for $D=0.15-0.20 \mathrm{~m}$ ), $1.25 \times 10^{-5} \mathrm{~m}$ (note: $k / D \approx 7.0 \times 10^{-5}$ for $D=0.15-0.20 \mathrm{~m}$ ). All of the test pipes are $0.48 \mathrm{~m}$ long, with $0.01 \mathrm{~m}$ gaps to the side walls.

As to a long-distance laid pipeline, the stability of pipeline at separate sections is different. For example, the demands for the stability of pipeline sections near risers are much higher than that of normal sections. Due to the constraints from risers and pipeline's own anti-torsion rigidity, the pipeline movement is neither purely parallel nor purely rotational. As such, the following two constraint conditions are considered:

Case I: Anti-rolling pipe. Pipeline rolling is restricted, but the pipeline can move freely in horizontal and vertical directions. An anti-rolling device was designed, with which the test pipe was attached to the two side walls of the sand box (see Fig. 2).

Case II: Freely-laid pipe. In this case, the anti-rolling device does not function, i.e. the test pipe may rotate around its axis without any end constraint.

A kind of medium silica sand-bed was adopted, whose grain size distribution is shown in Fig.3. Its mean particle diameter $d 50=0.38 \mathrm{~mm}$, and relative density $D r=0.66$, indicating that the sand sample is a medium-dense one. The buoyant unit weight of sand $\gamma^{\prime}=9.3 \mathrm{kN} / \mathrm{m}^{3}$, internal friction angle $\phi=26.7^{0}$, and the uniformity coefficient of sand $C_{u}=1.46$.

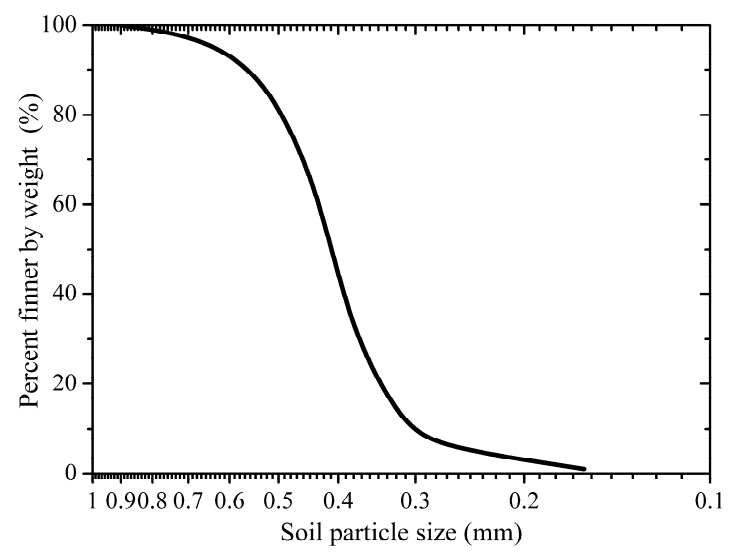

Fig.3. Grain size distribution curves of the test sand

The testing procedure was adopted as follows: (1) The test pipe was being laid downward to the soil surface, the laser displacement transducer (LDT-2) was triggered while the pipe touching at the sand-bed surface; (2) The pipe then settled into the sand-bed due to its self-weight; meanwhile the initial settlement of the pipe was measured with LDT-2; (3)After the initial settlement finished, the stepper motor was started to impose an inclined load onto the pipe via a cable passing through a fixed pulley, for simulating steady currents induced hydrodynamic forces. During the pipe breakout process, the pipe additional settlements and the corresponding loads were measured simultaneously. The phenomena were recorded with a digital video camera through the transparent side wall.

\section{EXPERIMENTAL RESULTS AND DISCUSSIONS}

\subsection{Typical features for pipe-soil interaction}

\section{(1) Case I: Anti-rolling pipe}

Fig.4 illustrates the typical test results on the settlement and lateral soil resistance for an anti-rolling pipe during losing lateral on-bottom stability. In this figure, $e_{y}$ is the settlement of the moving pipe, the negative signal means the settlement direction is downward. As shown in Fig. 4(a), the initial embedment due to pipe self-weight is $e_{0}=0.02 D$; while the pipe breaking out from its original site (or with increasing horizontal displacement of the pipe), some additional settlement was developed. When the horizontal displacement $S_{x}$ is approximately $0.25 D$, the total settlement reaches its maximum value $e_{m}=0.042 D$. Fig. 4(b) indicates that the horizontal lateral soil resistance $\left(F_{H}\right)$ increases gradually to its maximum value $\left(F_{u}=0.09 \mathrm{kN} / \mathrm{m}\right)$ when the additional settlement is nearly fully developed.

Experimental observation also indicates that, the breakout of anti-rolling pipe was always accompanied by forming a sand wedge due to the collection of sand particles in front of the moving pipe. That is, the buildup of the ultimate lateral soil resistance to the anti-rolling pipe benefits from both the additional settlements and the sand-particle collections.

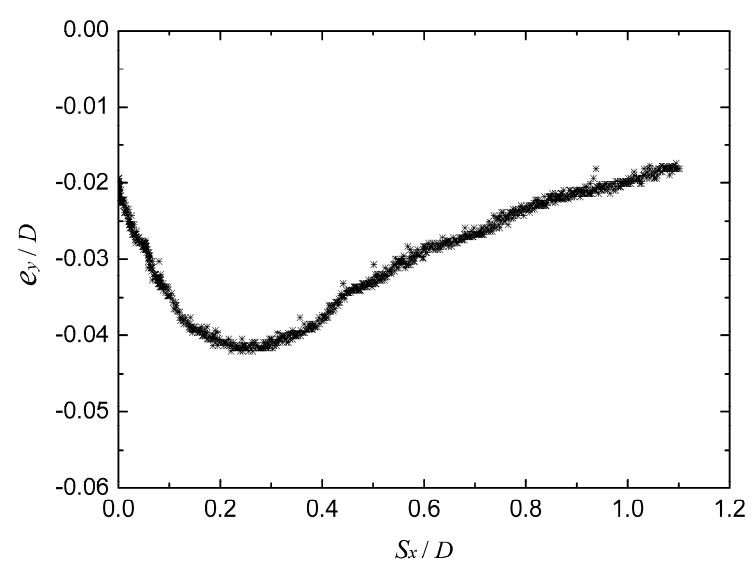

(a) 


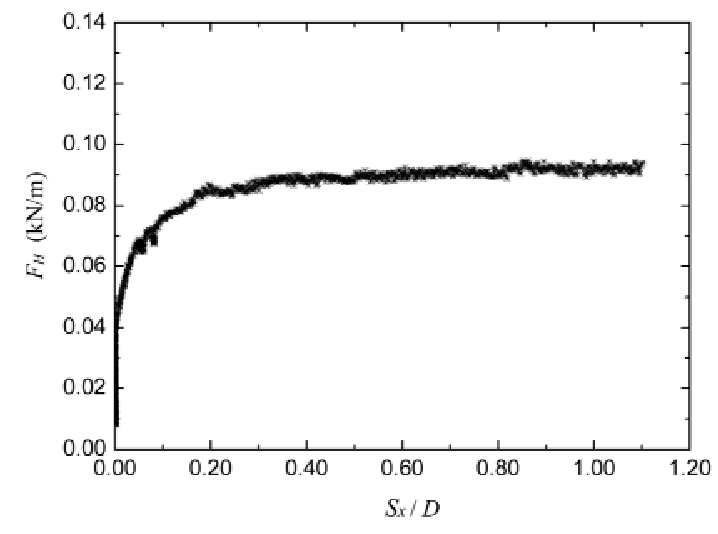

(b)

Fig.4 Settlement and lateral soil resistance for an anti-rolling pipe: (a) Settlement vs. horizontal displacement; (b) Lateral soil resistance vs. horizontal displacement $\left(D=0.15 \mathrm{~m}, W_{S}=0.225\right.$

$$
\mathrm{kN} / \mathrm{m}, k / D \approx 7.0 \times 10^{-5}, d 50=0.38 \mathrm{~mm}, \mathrm{Dr}=0.66 \text { ) }
$$

\section{(2) Case II: Freely-laid pipe}

The settlement and the lateral soil resistance for a freelylaid pipe were also investigated. Experimental observation shows that, without the anti-rolling constraint, the freely-laid pipe rotated along the soil surface, without obvious collection of the neighboring sand particles in front of the shallowlyembedded pipe while losing lateral stability.

The representative test results on the settlement and lateral soil resistance for a freely-laid pipe during losing lateral onbottom stability is illustrated in Fig. 5. Compared with the antirolling pipe (see Fig 4.(a)), the additional settlement for the freely-laid pipe is much less obvious (see Fig. 5(a)). The corresponding ultimate lateral soil resistance $\left(F_{u}=0.04 \mathrm{kN} / \mathrm{m}\right.$, see Fig. 5(b)) is much smaller than that for anti-rolling pipes (see Fig. 4(b)).

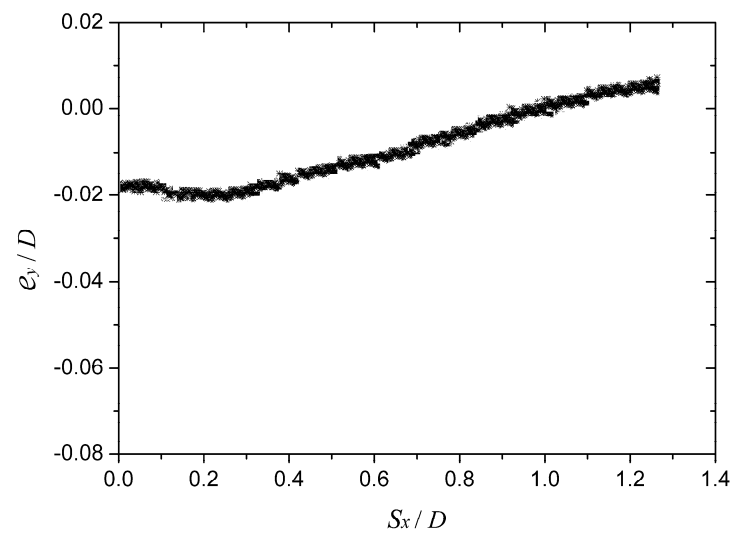

(a)

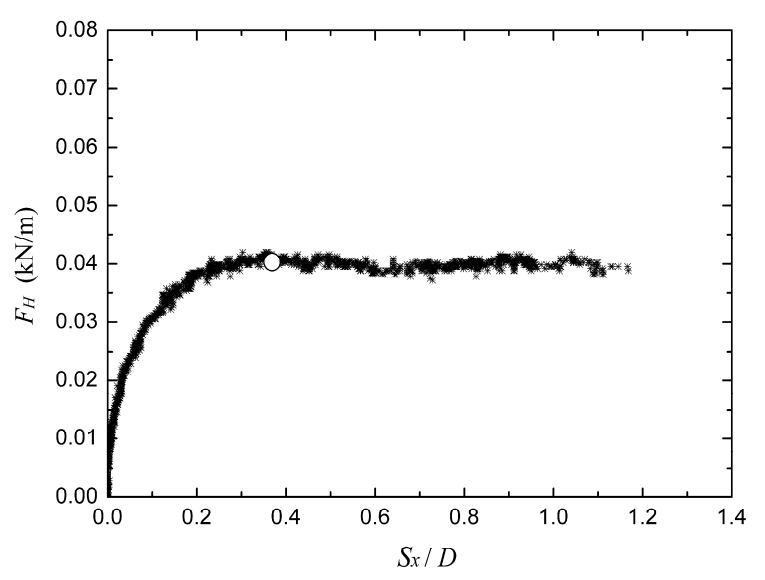

(b)

Fig.5 Settlement and lateral soil resistance for a freely-laid pipe: (a) Settlement vs. horizontal displacement; (b) Lateral soil resistance vs. horizontal displacement $\left(D=0.15 \mathrm{~m}, W_{S}=0.225\right.$

$$
\mathrm{kN} / \mathrm{m}, k / D \approx 7.0 \times 10^{-5}, d 50=0.38 \mathrm{~mm}, \mathrm{Dr}=0.66 \text { ) }
$$

\subsection{Effects of End Constraints}

Fig.6 shows the influence of constraint conditions on the maximum settlement and the lateral-soil-resistance coefficient for various dimensionless submerged weights.

As indicated in Fig. 6(a), for both the anti-rolling pipes and the freely-laid pipes, the maximum settlements increase with increasing the non-dimensional submerged weight of the pipe. The maximum settlements of anti-rolling pipes are obviously bigger than those of freely-laid pipes. Note that the pipe diameter has some effects on the relationship between $e_{m} / D$ and $G$. Fig. 6(b) gives the variation of lateral-soilresistances coefficients with the dimensionless submerged weight of the pipes. As shown in this figure, the lateral-soilresistances coefficient for anti-rolling pipes decreases slightly with the increase of non-dimensional submerged weight of the pipeline. For a certain value of non-dimensional submerged weight $(G)$, the lateral-soil-resistance coefficient for the antirolling pipe is much larger than that for the freely-laid pipe.

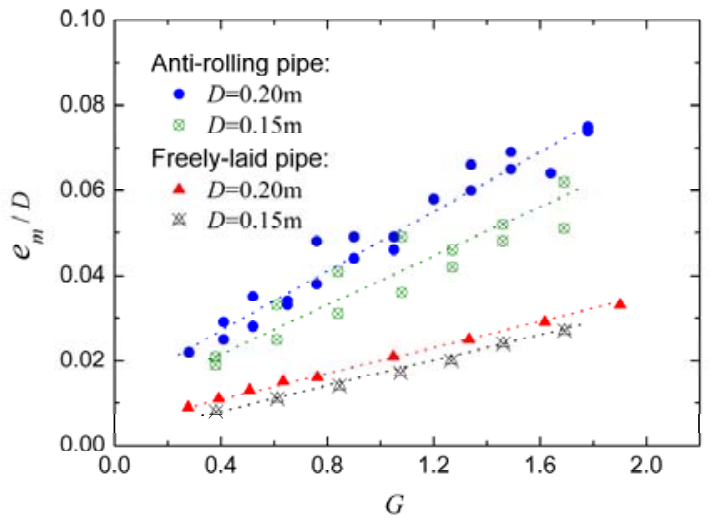

(a) 


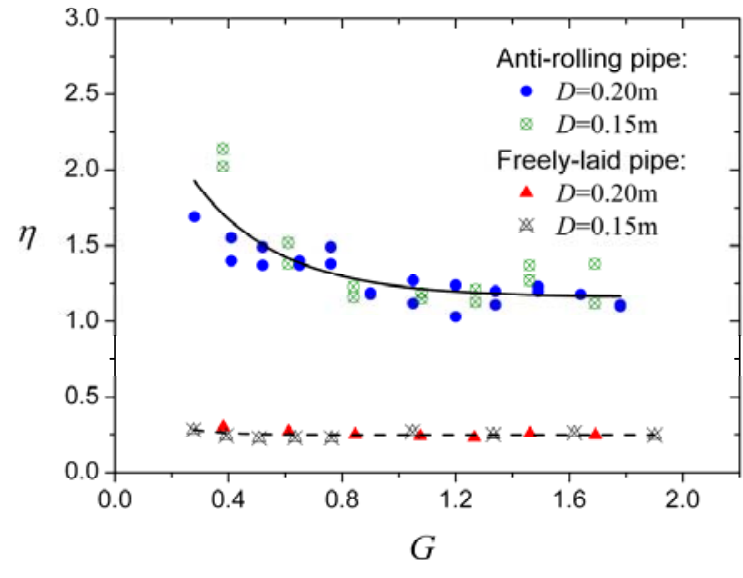

(b)

Fig.6 Effect of constraint conditions: (a) maximum settlement vs. non-dimensional pipe weight; (b) lateral-soil-resistance coefficient vs. non-dimensional pipe weight $\left(k / D \approx 6.0 \times 10^{-4}\right.$,

$$
d 50=0.38 \mathrm{~mm}, \operatorname{Dr}=0.66 \text { ) }
$$

\subsection{Effects of Pipe Surface Roughness}

As indicated in the aforementioned dimensional analysis, the pipe surface roughness may have influences on the pipesoil interactions. To this aim, two values of pipe surface roughness were considered, i.e. $k / D \approx 6.0 \times 10^{-4}, 7.0 \times 10^{-5}$.

Fig. 7 shows the experimental results of the effects of pipe surface roughness on the development of pipe settlement and the corresponding lateral soil resistance during an anti-rolling pipe breaking out from its original site. Fig. 7(a) shows that, the initial embedment for the rougher pipe $\left(e_{0} / D=0.013\right.$ for the pipe with $\left.k / D=6.0 \times 10^{-4}\right)$ is smaller than that for the smoother pipe $\left(e_{0} / D=0.022\right.$ for $\left.k / D=7.0 \times 10^{-5}\right)$. Nevertheless, the maximum embedment in the breakout process for the rougher pipe $\left(e_{m} / D=0.050\right.$ for $\left.k / D=6.0 \times 10^{-4}\right)$ gets much bigger than that for the smoother pipe $\left(e_{m} / D=0.041\right.$ for $\left.k / D=7.0 \times 10^{-5}\right)$. The ultimate lateral resistance is increased correspondingly with the increase of the maximum embedment (see Fig. 7(a) and (b)).

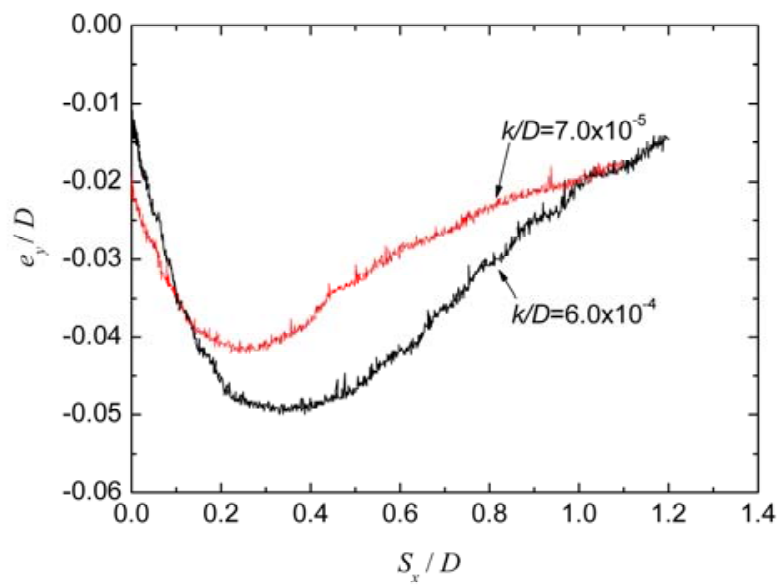

(a)

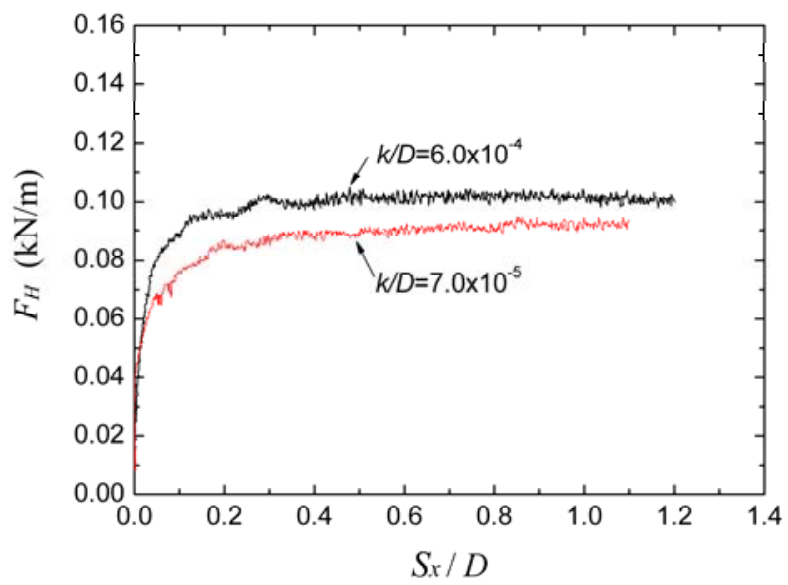

(b)

Fig.7 Effects of pipe surface roughness for anti-rolling pipes:

(a) settlement vs. horizontal displacement, (b) lateral-soilresistance and horizontal displacement $\left(D=0.15 \mathrm{~m}, W_{S}=0.225\right.$

$$
\mathrm{kN} / \mathrm{m}, d 50=0.38 \mathrm{~mm}, D_{r}=0.66 \text { ) }
$$

A series of tests has been conducted for the two values of pipe surface roughness (see Fig. 8). As shown in Fig. 8, for a certain value of dimensionless pipe weight, the lateral-soilresistance coefficient for the rough pipe $\left(k / D=6.0 \times 10^{-4}\right)$ is bigger than that for the smooth pipe $\left(k / D=7.0 \times 10^{-5}\right)$. The correlation of $\eta$ with $G$ gets ignorable for the smooth pipes. 


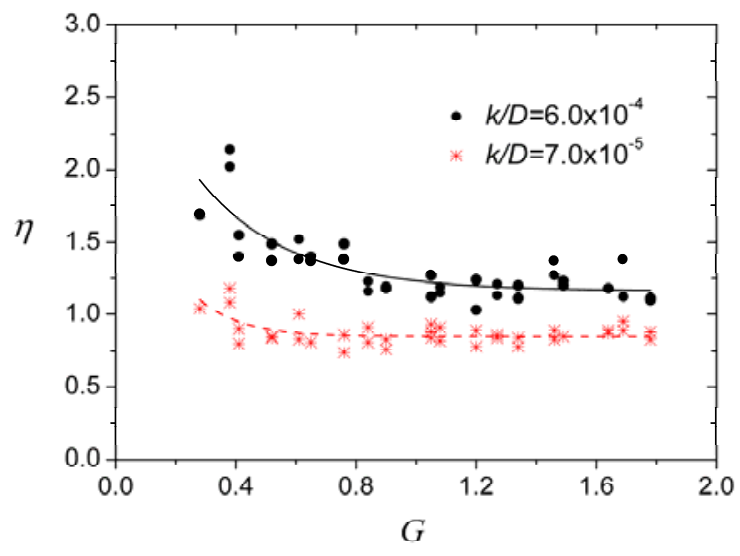

Fig. 8 Variation of lateral-soil-resistance coefficient with the dimensionless pipe weight for two values of surface roughness for anti-rolling pipes

\subsection{Comparison with the Results of Water Flume Tests}

The present mechanical actuator tests have advantages for revealing the pipe-soil interaction mechanism at the prototype-scale level. The pipeline on-bottom stability has also been investigated with water flume tests for various hydrodynamic loading conditions including waves and/or currents. It would be interesting and worthy to make a comparison between the results of the different types of tests.

Based on similarity theory analyses and a series water flume tests, Gao et al. (2007) [1] has established the empirical relationship between critical Froude number $\left(F r_{c r}\right)$ and the dimensionless submerged weight of pipe $(G)$ for describing the lateral stability of the freely-laid pipes in currents. The critical Froude number $\left(\mathrm{Fr}_{c r}\right)$ :

$$
\mathrm{Fr}_{c r}=U_{c r} / \sqrt{g D}
$$

in which $U_{c r}$ is the critical flow velocity for pipe losing lateral stability. For the comparison purpose, the corresponding $U_{c r}$ for the present mechanical actuator tests can be calculated by submitting the ultimate lateral resistance $\left(F_{u}\right)$ into the Morison's equations (see Eq. (5)).

Fig. 9 gives the comparison of $\mathrm{Fr}_{c r}-\mathrm{G}$ relationships between the results of the present mechanical-actuator tests and those of the water-flume tests by Gao et al. (2007). It is indicated that these experimental results are comparable. For the same value of non-dimensional pipe submerged weight $(G)$, the values of $\mathrm{Fr}_{c r}$ for the present mechanical actuator tests are slightly greater than those for the water-flume tests when increasing the non-dimensional pipe submerged weight. Note that, in the small-scale water-flume tests, local scour around the pipe was observed in the process of the pipe losing lateral stability under the action of currents. The local scour may reduce the pipeline lateral stability.

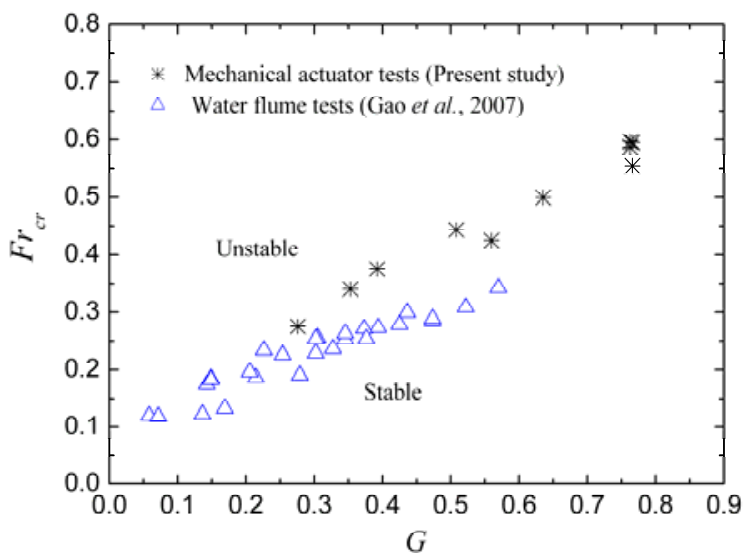

Fig. 9 Comparison of $\mathrm{Fr}_{c r}-\mathrm{G}$ relationship between the results of present mechanical-actuator tests and those of water-flume tests by Gao et al. (2007).

\section{CONCLUDING REMARKS}

The mechanical-actuator simulation method was adopted in this study to simulate the hydrodynamic loads on the pipe resting on the seabed. A series of pipe-soil interaction tests at the prototype-scale level have been conducted with the newly developed pipe-soil interaction facility, in order to determine the ultimate lateral soil resistance for the pipe breakout from sand-bed under the action of ocean currents.

The experimental observations indicate that, the horizontal lateral soil resistance increases gradually to its maximum value when the additional settlement is fully developed. The buildup of the ultimate lateral soil resistance to the anti-rolling pipe benefits from not only the additional settlements but also the sand-particle collections in front of the moving pipe, especially for the anti-rolling pipes. For a certain value of nondimensional submerged weight, the lateral-soil-resistance coefficient for the anti-rolling pipe is much larger than that for the freely-laid pipe. The lateral-soil-resistance coefficients for the anti-rolling rough pipes are bigger than those for the smooth pipes. Comparison of $\mathrm{Fr}_{\mathrm{cr}}-\mathrm{G}$ relationships between the results of the present mechanical-actuator tests and those of the previous water-flume tests, indicating the results of two types of tests are comparable and the local scour may reduce the pipe lateral stability in ocean currents.

\section{ACKNOWLEDGMENTS}

This work is financially supported by China National S\&T Major Project (No. 2008ZX05026-005) and Knowledge Innovation Program of the Chinese Academy of Sciences (No. KJCX2-YW-L02). Technical assistances from Dr. Bing Yang, Mr. Chengcai Luo and Mr. Bo Zhao in the experiments are also greatly appreciated. 


\section{REFERENCES}

[1] Gao, F. P., Yan, S.M., Yang, B., Wu, Y. X., 2007, “ocean currents induced pipeline lateral stability on sandy seabed”, Journal of Engineering Mechanics, ASCE, 133(10): 1086-1092.

[2] Braestrup, M. W., Andersen, J. B., Andersen, L. W., Bryndum, M., Christensen, C. J., Niels-Jørgen Rishøj Nielsen., 2005, "Design and Installation of Marine Pipelines”, M, Blackwell Publishing.

[3] Lyons, C.G., 1973, "Soil resistance to lateral sliding of marine pipeline”, Proceedings of Fifth Annual Offshore Technology Conference, OTC 1876, 479-484.

[4] Wagner, D. A., Murff, J. D., Brennodden, H., and Sveggen, O., 1987, "Pipe-soil interaction model”, Proceedings of Nineteenth Annual Offshore Technology Conference, OTC 5504, 181-190.

[5] Brennodden, H., Lieng, J. T., Sotberg, T., and Verley R. L. P., 1989. “An energy-based pipe-soil interaction model”, Proceedings of 21st Annual Offshore Technology Conference, OTC 6057, 147-158.

[6] Palmer, A. C., Steenfelt, J. S. and Jacobsen, V., 1988, "Lateral resistance of marine pipelines on sand", Proceedings of 20th Annual Offshore Technology Conference, OTC 5853, 399-408.

[7] Brennodden, H., Sveggen, O., Wagner, D. A., and Murff, J. D., 1986, "Full-scale pipe-soil interaction tests", Proceedings of Eighteenth Annual Offshore Technology Conference, OTC 5338, 433-440.

[8] Verley, R.L.P. and Sotberg, T., 1992, "A soil resistance model for pipeline placed on sandy soils.” OMAE, Vol. VA, Pipeline Technology, 123-131.

[9] Verley, R.L.P. and Lund, K.M., 1995, “A soil resistance model for pipeline placed on sandy soils”, OMAE, Vol. VA, Pipeline Technology, 225-232.

[10] Zhang, J., Stewart, D. P., Randolph, M. F., 2002, "Modeling of shallowly embedded offshore pipelines in calcareous sand", Journal of Geotechnical and Geoenvironmental Engineering, ASCE, Vol. 128, 363371.

[11] Jones, W. T., 1978, “On-bottom pipeline stability in steady water currents”, Journal of Petroleum Technology, Vol. 30, 475-484 